Article

\title{
The Pattern of Superficial Body Temperatures in Leisure Horses Lunged with Commonly Used Lunging Aids
}

\author{
Malgorzata Maśko ${ }^{1, * \mathbb{D}}$, Lukasz Zdrojkowski ${ }^{2}$, Malgorzata Domino ${ }^{2}$, Tomasz Jasinski ${ }^{2}$ and \\ Zdzislaw Gajewski ${ }^{2}$ \\ 1 Department of Animal Breeding, Faculty of Animal Science, Warsaw University of Life \\ Sciences (WULS-SGGW), 02-787 Warsaw, Poland \\ 2 Department of Large Animal Diseases with Clinic, Veterinary Research Centre and Center for Biomedical \\ Research, Faculty of Veterinary Medicine, Warsaw University of Life Sciences (WULS-SGGW), \\ 02-787 Warsaw, Poland; lukasz_zdrojkowski@sggw.pl (L.Z.); malgorzata_domino@wp.pl (M.D.); \\ tomasz_jasinski@sggw.pl (T.J.); zdzislaw_gajewski@sggw.pl (Z.G.) \\ * Correspondence: malgorzata.masko@gmail.com; Tel.: +48-609-346-669
}

Received: 1 October 2019; Accepted: 4 December 2019; Published: 7 December 2019

Simple Summary: In the training of horses, special lunging aids may be used to regulate head and neck position during exercise without the intervention of a rider. The rubber band and triangle side reins and the chambon have an impact on thoracolumbar kinematics and the motion of the fore- and hindlimbs. Lunging aids are assumed to modulate the work of horses' muscles, which results in altering the superficial thermographic patterns. Thermography is a non-invasive, contactless imaging technique based on detecting emitted infrared radiation representing the temperature of the body surface, influenced by muscle metabolism and blood circulation. Training sessions for 16 horses performed in the study included exercises at walk, freely active trot, and canter. Surface temperatures of 11 regions of interest were evaluated on all images, corresponding to areas influenced by neck fixation and engaging hindquarters. In conclusion, thermography was shown as a useful tool in lunging aids' usefulness evaluation. Different types of lunging aids influence the mobility of horse neck and back and its choice for leisure horses lunging should be made individually. Lunging aids change the surface temperature of different body parts during the leisure horse work on the lunge.

\begin{abstract}
Background: The natural head and neck position (HNP) of horses differs from the position in horse riding when bit is used. The special lunging aids (LAs) are applied in order to modify HNP. Different types of LAs have the potential to affect the work of horse muscles and the superficial thermographic patterns (STPs). The effects of thre LAs on STPs of neck, chest, back, and hindquarters were investigated. Methods: Sixteen leisure horses were lunged with freely moving head (FMH), rubber band (RB), chambon $(\mathrm{CH})$, and triangle side reins (TRs). The thermographic images $(n=896)$ were analyzed before/after lunging for mean temperatures $\left(\mathrm{T}_{\text {mean }}\right)$ and minimum-maximum difference ( $\left.\mathrm{T}_{\text {diff }}\right)$. Results: Superficial $\mathrm{T}_{\text {mean }}$ increased $(p<0.001)$ in cranial part of neck, back, thoracic area, and limbs after lunging regardless of LAs application or its type. In comparison to other LAs: With RB, $\mathrm{T}_{\text {mean }}$ was higher in regions of interest (ROIs) 2,7 and lower in ROIs 3-4 $(p<0.05)$; with $\mathrm{CH}, \mathrm{T}_{\text {mean }}$ was higher in ROIs $2-4$ and $7(p<0.01)$; and with TRs, $\mathrm{T}_{\text {mean }}$ was higher in ROIs $2-4,7,9-11(p<0.01)$. In ROIs $2-4$ and 7 , $\mathrm{T}_{\text {diff }}$ was lower with LAs than with FMH $(p<0.01)$ and in ROIs 9-10 with TRs. Conclusions: The choice of LAs should be dictated by the expected effect; however, all LAs increase the quality of the leisure horse lunging. LA use is more desirable than lunging with FMH.
\end{abstract}

Keywords: rubber band; chambon; triangle side reins; lunging; head and neck position; leisure horses; thermography 


\section{Introduction}

The natural head and neck position (HNP) is typical for horses without any load. The freely running horse lowers the head/neck base and relaxes the muscles with open head/neck angle (HNA) [1], whereas in saddle use, HNA often remains closed [2]. In the training of horses, special lunging aids (LAs) are applied in order to regulate HNP during exercise without the intervention of a rider $[3,4]$. The LAs modify HNP by forces acting on the bit, head, breast, girth, and withers. The rubber band (RB) and triangle side reins (TRs) close HNP, whereas the chambon $(\mathrm{CH})$ opens it [5]. The impact of HNP on thoracolumbar kinematics [6] and the motion of the fore- and hindlimbs [5] was previously described; therefore, the LA may also be assumed to modulate the work of horses' muscles and deep stabilizing structures of ligaments [7]. This modulation depends both on the differing degree of reins' tension/elasticity and the length of the aids causing the more loose or tight attachment $[5,7]$. The RB represents compliant elastic reins, whereas TRs are the stiffest [8]. Every LA can be used with different length; therefore, the comparison between their types should consider the aids length individually matched to the horse or target HNP.

The research was conducted on the leisure horses. Horses in leisure usage, which is recreation, differ sports usage, considered as competitive in Olympic disciplines on different levels, and racing usage, considered as participating in races $[9,10]$. The difference between sports or racing usage and leisure usage may be defined based on determining the activity initiator and the purposes of training. In sports or racing usage, only the human participants are responsible for taking the initiative during the training, which is conduct for specific purposes such as raising the skills needed in Olympic disciplines or races. Whereas, in a case of leisure usage, especially riding outdoors in the fields or the forest, also the horse may take the initiative under human control, and the main goal of the training is relaxation and active rest [11].

We suppose that an application of a different type of LAs has the potential to affect the work of horse muscles, which results in altering the superficial thermographic patterns (STPs), compared to lunging with a freely moving head (FMH). Differences between the freely moving and fixed head may affect blood circulation in the muscles because of the forced change of HNP [4]. The increase in blood circulation occurs when muscle tension in a particular region is increased [12], whereas insufficient blood circulation decreases muscle oxygenation and affects metabolism [13]. Superficial muscles blood circulation affects STP, which may be assessed with thermography. Thermography is a non-invasive, contactless imaging technique based on detecting emitted infrared radiation representing the temperature of body surface [14], influenced by muscle metabolism and blood circulation $[15,16]$. Soroko et al. (2012) described changes of back temperature distribution in response to training cycle [17], whereas Simon et al. (2006) presented temperatures of fore- and hindlimbs during training sessions on the treadmill [15]. The STP of the head/neck region was also assessed to determine differences in blood circulation in the musculature between hyperflexion and FMH [4]. In all these studies the specific areas of body surface were chosen for statistical analysis of thermographic data to quantify the thermographic images. Those areas, named further as regions of interest (ROIs), represent the work of the large muscle groups significantly involved in horse mobility in the neck, chest, back, and hindquarters, following Becker-Birck et al. (2013), Soroko et al. (2012), and Simon et al. (2006), respectively $[4,15,17]$.

The objective of this study was to evaluate STPs of the different regions of the horse- the neck, chest, back, and hindquarters-as well as compare patterns obtained from the same horses after lunging with and without LAs. Three types of LAs were verified: rubber band, chambon, and triangle side reins.

\section{Materials and Methods}

Sixteen horses participated in the study ( 7 mares, 9 geldings, mean age $12.7 \pm 3.6$ years) of three Polish warmblood breeds (56\% Malopolska; $11 \%$ Wielkopolska; 33\% Polish Halfbred horse) and four horse handlers from the Animal Sciences Students Ridden Association. All horses were housed in 
individual stalls with the same management in the Didactic Stable of Horse Breeding Division at WULS. The horses were fed three times a day with a dose of oats and hay personalized to each horse to maintain optimal, healthy condition without obesity, and had daily access to a sandy paddock no shorter than $6 \mathrm{~h}$ per day. All horses were in daily leisure use, considered as recreational riding 1 to $2 \mathrm{~h}$ a day, five days a week, also including lunging with FMH and LAs. The thermal imaging was performed following the international veterinary standards [18], and the health status and the mouth condition were inspected before the experiment [19]. Horses were clinically healthy, with no dental disorders or any signs of ulceration in mouth examination, and demonstrated a comparable condition and athletic ability.

All horses were tested using the same procedure in the same order: without aids, with $\mathrm{RB}, \mathrm{CH}$, and TRs. The LA was always used with comparable length adjusted to each horse basing on the HNA measured each time on the image. The HNA of a horse under these conditions was $\alpha: 110^{\circ}-115^{\circ}$ without reins and with $\mathrm{CH}$ (Figure $1 \mathrm{~A}, \mathrm{~B}$ ), while $\mathrm{B}$ : $85^{\circ}-90^{\circ}$ with an RB or TRs (Figure $\left.1 \mathrm{C}, \mathrm{D}\right)$. The HNPs were tested for four consecutive days, one for each position.
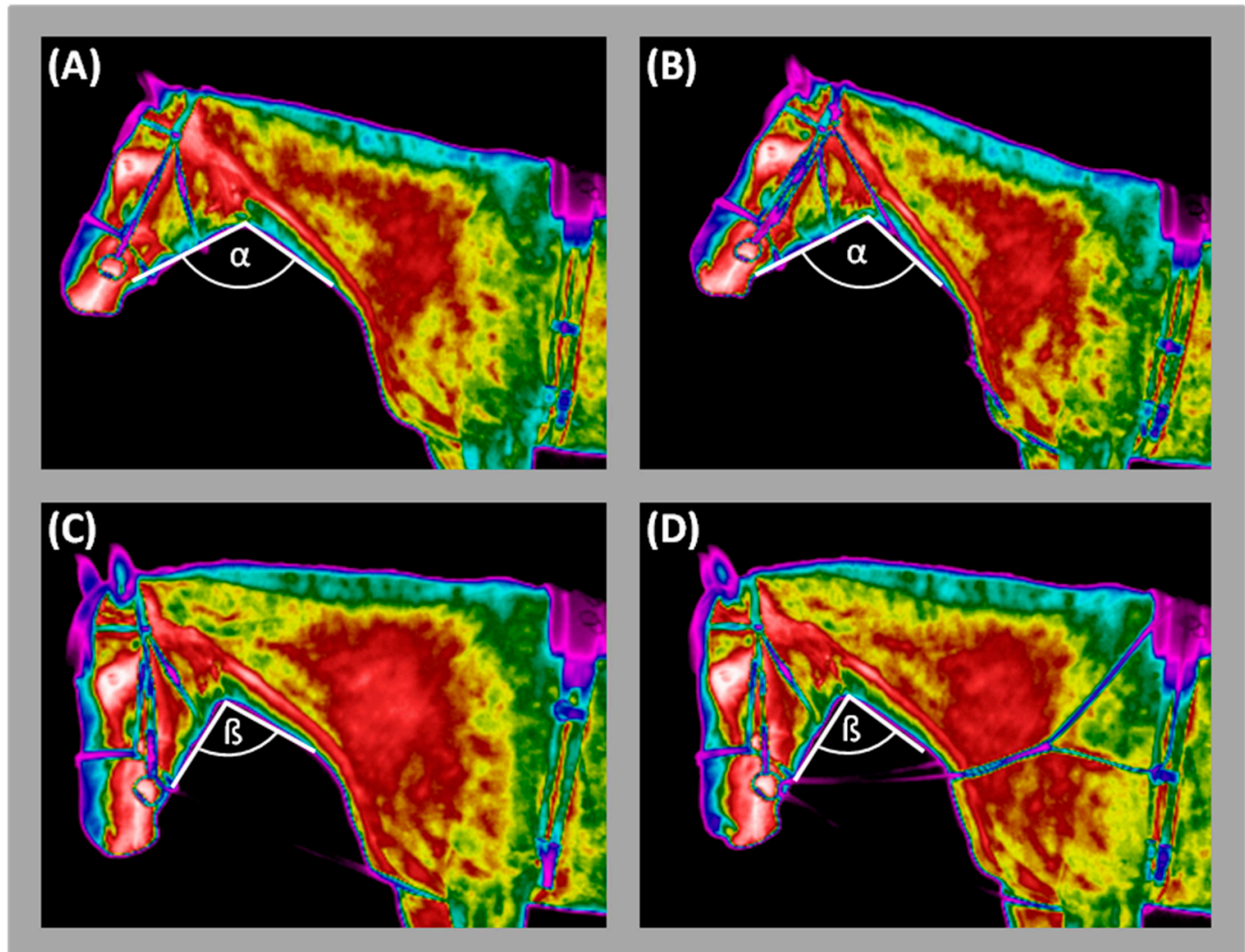

Figure 1. Thermographic image of horse lunged with: (A) freely moving head, (B) chambon, (C) rubber band, (D) triangle side reins. The open head and neck position marked with $\alpha: 110^{\circ}-115^{\circ}$; the close head and neck position marked with $B: 85^{\circ}-90^{\circ}$. The dashed lines marked the location of subsequent lunging aids.

A total of 896 images were taken before and after training sessions in an indoor ridden hall (ambient temperature $20.2{ }^{\circ} \mathrm{C} \pm 1.1$ ), protected from wind and sun radiation, and connected with the stable in which horses were housed. Images were taken using an infrared radiation camera (VIGOcam.v50, VIGOSystem S.A., Ozarow Mazowiecki, Poland) with an emissivity (e) that ranged from 0.99 to 1.00 and a temperature range $20-40^{\circ} \mathrm{C}$. The camera was handheld at a distance of approximately $1.2 \mathrm{~m}$ up from the horse, at right angles to the imaged plane- the lateral plane of the neck and hindquarters, the frontal plane of the chest, the dorsal plane of the back, and the caudal plane of hindquarters. 
Each data collection started with bringing one horse at a time from the stable, letting it stand in the middle of the riding hall to take the baseline pictures. Then training sessions started and included exercises in both directions at walk, freely active trot, and canter, individually adjusted to each horse for the appropriate tempo: walk (up to $1.5 \mathrm{~m} / \mathrm{s}$ ), trot (up to $4.0 \mathrm{~m} / \mathrm{s}$ ), and canter (up to $6.0 \mathrm{~m} / \mathrm{s}$ ). The total duration of each session was $50 \mathrm{~min}$ and included $10 \mathrm{~min}$ of walk, $10 \mathrm{~min}$ of trot, $5 \mathrm{~min}$ of canter, again $10 \mathrm{~min}$ of trot, again $5 \mathrm{~min}$ of canter, then $5 \mathrm{~min}$ of trot, and finally $5 \mathrm{~min}$ of walk. After the second imaging, the horses were walked on the rope to complete rest.

Surface temperatures of 11 regions of interest (ROIs 1-11) were evaluated on all 896 images according to criteria described in Table 1 . Consecutive ROIs (1-4) correspond to areas influenced by neck fixation. Via analyses of ROIs 5-11, we are able to determine if and how fixation of neck obtained by lunging aids is altering muscles activity in other body parts of the horse. (Figure 2).

Table 1. The characteristic of regions of interest (ROIs) taken into consideration in the examined superficial thermographic patterns.

\begin{tabular}{|c|c|c|}
\hline No & Shape of ROI & Range of ROI \\
\hline ROI 1 & a line & $\begin{array}{l}\text { from the highest point of the horses' nape of the neck to the ventral } \\
\text { guttural angle }\end{array}$ \\
\hline ROI 2 & an ellipse & $\begin{array}{l}\text { from the caudal aspect of the mandible to the ventral and dorsal lines of } \\
\text { the neck }\end{array}$ \\
\hline ROI 3 & a circle & $\begin{array}{l}\text { from the cranial brim of the saddle flap onto the neck and from the } \\
\text { height of the shoulder joint to the upper aspect of the mane }\end{array}$ \\
\hline ROI 4 & $\begin{array}{l}\text { an irregular, } \\
\text { trapezoidal }\end{array}$ & $\begin{array}{l}\text { from the line between the highest point of the neck and the ventral } \\
\text { guttural angle to the line between the height of the shoulder joint and } \\
\text { the highest spinous process of thoracic vertebrae, represents whole neck } \\
\text { muscles work }\end{array}$ \\
\hline ROI 5 & $\begin{array}{l}\text { an irregular, } \\
\text { L-shaped }\end{array}$ & $\begin{array}{l}\text { from the upper half of the middle chest line, horizontally to and along } \\
\text { the lateral, upper edge of the pectoral muscles up to the middle of the } \\
\text { spine of scapula }\end{array}$ \\
\hline ROI 6 & $\begin{array}{l}\text { an irregular, } \\
\text { trapezoidal }\end{array}$ & $\begin{array}{l}\text { from the lower half of the middle chest line, horizontally to and along } \\
\text { the lateral, lower edge of the pectoral muscles down to the manubrium } \\
\text { of the sternum }\end{array}$ \\
\hline ROI 7 & a rectangle & $\begin{array}{l}\text { from the highest spinous process of thoracic vertebrae to the last sacral } \\
\text { vertebrae }\end{array}$ \\
\hline ROI 8 & $\begin{array}{l}\text { an irregular, } \\
\text { barrel-shaped }\end{array}$ & $\begin{array}{l}\text { from the middle of thoracic vertebrae along the last rib to the widest } \\
\text { line of the chest and up to the highest spinous process of thoracic } \\
\text { vertebrae along the caudal edge of the scapula }\end{array}$ \\
\hline ROI 9 & $\begin{array}{l}\text { an irregular, } \\
\text { hourglass-shaped }\end{array}$ & $\begin{array}{l}\text { from the highest point of ilium down to the knee joint along the tail } \\
\text { contour to the lateral edge of the semitendinosus muscle }\end{array}$ \\
\hline ROI 10 & $\begin{array}{l}\text { an irregular, } \\
\text { fusiform }\end{array}$ & $\begin{array}{l}\text { from anterior superior iliac spine to the knee joint, between the lateral } \\
\text { edge of semitendinosus muscle and the lateral edge of the hindquarters }\end{array}$ \\
\hline ROI 11 & $\begin{array}{l}\text { an irregular, } \\
\text { barrel-shaped }\end{array}$ & $\begin{array}{l}\text { from sacral vertebrae down to the knee joint along the caudal edge of } \\
\text { hindquarters and along patella up to the coxal tuber }\end{array}$ \\
\hline
\end{tabular}

The symmetrical regions (ROIs 1-6, ROIs 8-11) were taken under consideration independently for left and right side. Each ROI was analyzed according to the protocol proposed by Becker-Birck et al. (2013) for the minimum $\left(T_{\min }\right)$, maximum $\left(T_{\max }\right)$, and mean $\left(T_{\text {mean }}\right)$ temperatures measured with the THERMCAM software (VIGOSystems S.A., Ozarow Mazowiecki, Poland). Then the minimum-maximum difference $\left(\mathrm{T}_{\text {diff }}\right)$ was calculate based on $\mathrm{T}_{\min }$ and $\mathrm{T}_{\max }$ measures [4]. 

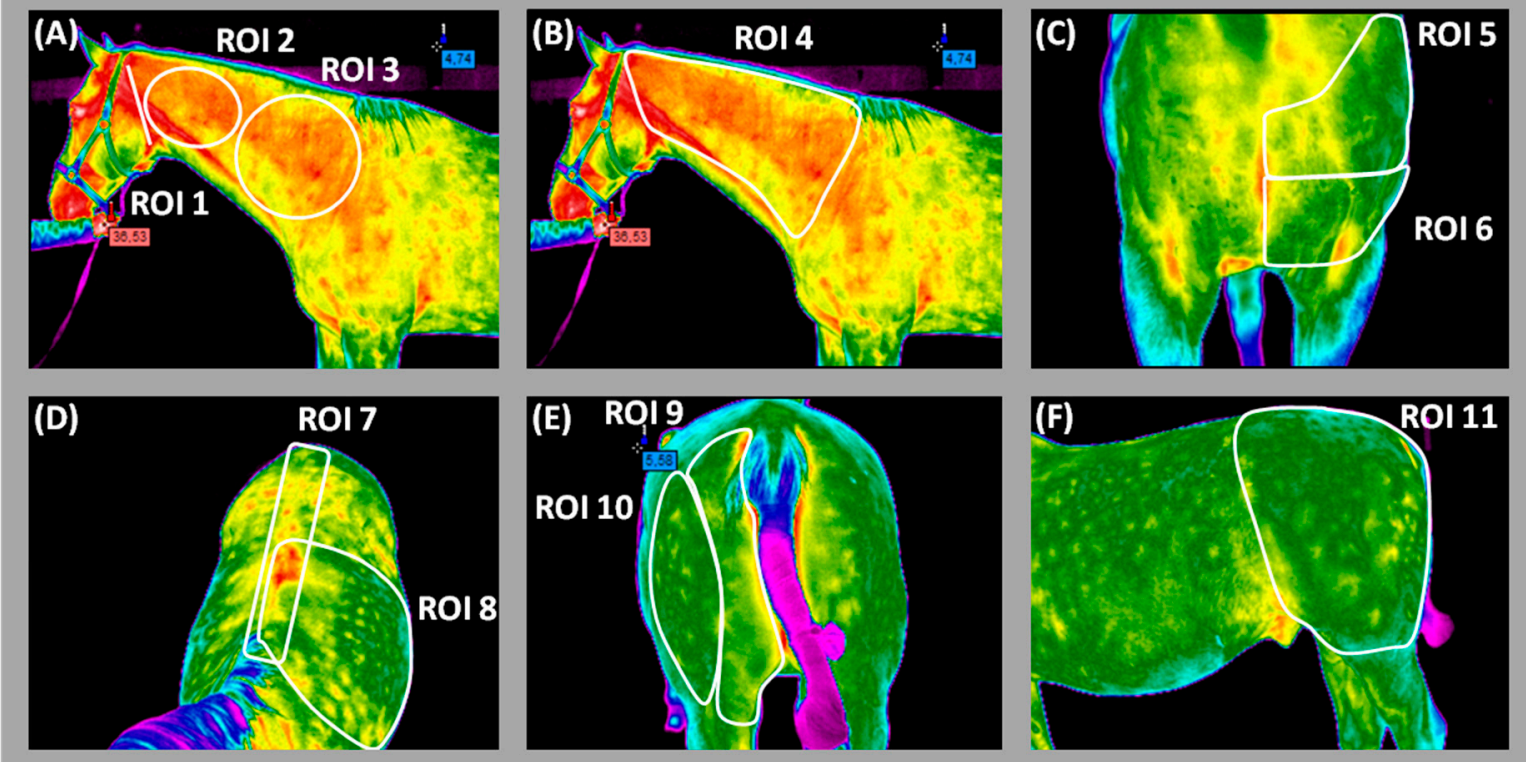

Figure 2. The regions of interest (ROIs) chosen for statistical analysis of thermographic data: (A) ROIs 1-3, (B) ROI 4, (C) ROIs 5-6, (D) ROIs 7-8, (E) ROIs 9-10, (F) ROI 11.

Obtained data were represented in the form of numerical series representing measurements before and after an effort, as well as among FMH and type of lunging aid used. Each data series was tested independently for univariate marginal distributions using a univariate Kolmogorov-Smirnov test. Most of the data series obtained for ROIs 1-11 in the examined HNPs (FMH, RB, CH, TRs) represented Gaussian distribution when the $\mathrm{T}_{\min }, \mathrm{T}_{\max }, \mathrm{T}_{\text {mean }}, \mathrm{T}_{\text {diff }}$ were taken under consideration. On the other hand, after effort, non-Gaussian distribution in the following data series was found: $\mathrm{T}_{\text {mean }}$ in ROIs 4, 6 , 8 when the horses were lunged with FMH and RB; $\mathrm{T}_{\min }$ in ROI $1(\mathrm{CH})$ and ROI 7 (TRs); $\mathrm{T}_{\max }$ in ROI 2 (RB) and ROI $6(\mathrm{CH})$; as well as $\mathrm{T}_{\text {diff }}$ in ROI $6(\mathrm{FMH})$ and ROI $8(\mathrm{CH})$.

Firstly, data series of all measurements $\left(\mathrm{T}_{\min }, \mathrm{T}_{\max }, \mathrm{T}_{\text {mean }}, \mathrm{T}_{\text {diff }}\right)$ obtained from the right and left side were compared using Unpaired t-test with Welch's correction (for Gaussian distribution of all data series) or the Mann-Whitney test (for non-Gaussian distribution of at least one data series). Next, the data series of two measurements ( $T_{\text {mean }}, T_{\text {diff }}$ ) were compared to estimate the differences between measurements among FMH and type of lunging aid used. For this purpose, one-way ANOVA test followed by Tukey's multiple (for Gaussian distribution), or Kruskal-Wallis test with Dunn's multiple comparisons test (for non-Gaussian distribution), was used. Finally, again the data series of two measurements ( $T_{\text {mean }}, T_{\text {diff }}$ ) were tested using unpaired $t$-test with Welch's correction (for Gaussian distribution) or the Mann-Whitney test (for non-Gaussian distribution) to distinguish the differences before and after an effort. All statistical analysis was performed using GraphPad Prism6 software (GraphPad Prism 6; GraphPad Software Inc., San Diego, CA, USA), where the significance level was established as $p<0.05$.

\section{Results}

The values of $\mathrm{T}_{\min }, \mathrm{T}_{\max }, \mathrm{T}_{\text {mean }}$, and $\mathrm{T}_{\text {diff }}$ (data not shown) in all 11 analyzed ROIs did not show any differences between right and left side both before and after effort. $\mathrm{T}_{\text {mean }}$ was determined for each ROI, and the values of $T_{\min }, T_{\max }$ were used to calculate $T_{\text {diff }}$; therefore, the mean $\pm S D$ values of $T_{\text {mean }}$ and $\mathrm{T}_{\text {diff }}$ were summarized in Tables 2 and 3, respectively, to demonstrate the changes in the pattern of superficial body temperatures in leisure horses lunged with commonly used lunging aids. 
Table 2. The values (mean $\pm \mathrm{SD}$ ) of $\mathrm{T}_{\text {mean }}$ obtained before and after lunging with: freely moving head, rubber band, chambon, and triangle side reins. The values represent the superficial thermographic patterns of regions of interest (ROIs) of the neck (ROIs 1-2), chest (ROIs 5-6), back (ROIs 7-8), and hindquarters (ROIs 9-11). The first superscript letters $\left({ }^{a}, b\right)$ indicate differences between measurements before and after an effort independently for each head and neck position. The second superscript letters $\left({ }^{v}, x, y, z\right)$ indicate differences between freely moving head and type of lunging aid used before $\left({ }^{v}\right)$ and after $\left({ }^{x}, y, z\right)$ effort. The differences were significant for $p<0.05$, independently for each row.

\begin{tabular}{|c|c|c|c|c|c|c|c|c|}
\hline \multirow{2}{*}{$\begin{array}{c}\text { Lunging } \\
\text { ROIs }\end{array}$} & \multicolumn{2}{|c|}{ Freely Moving Head } & \multicolumn{2}{|c|}{ Rubber Band } & \multicolumn{2}{|c|}{ Chambon } & \multicolumn{2}{|c|}{ Triangle Side Reins } \\
\hline & Before Lunging & After Lunging & Before Lunging & After Lunging & Before Lunging & After Lunging & Before Lunging & After Lunging \\
\hline ROI 1 & $28.05 \pm 2.24^{\mathrm{a}, \mathrm{v}}$ & $31.36 \pm 2.18^{b, x}$ & $27.67 \pm 2.52^{a, v}$ & $33.67 \pm 1.15^{b, x}$ & $28.17 \pm 1.76^{\mathrm{a}, \mathrm{v}}$ & $33.60 \pm 0.96^{b, x}$ & $29.00 \pm 1.00^{\mathrm{a}, \mathrm{v}}$ & $34.11 \pm 1.00^{b, x}$ \\
\hline ROI 2 & $26.91 \pm 1.53^{a, v}$ & $32.31 \pm 1.67^{b, x}$ & $28.64 \pm 2.03^{a, v}$ & $36.37 \pm 2.15^{b, y}$ & $28.55 \pm 2.36^{\mathrm{a}, \mathrm{v}}$ & $36.64 \pm 2.60^{b, y}$ & $29.72 \pm 1.60^{\mathrm{a}, \mathrm{v}}$ & $37.87 \pm 1.42^{b, y}$ \\
\hline ROI 3 & $29.51 \pm 1.19^{\mathrm{a}, \mathrm{v}}$ & $33.29 \pm 1.37^{b, x}$ & $31.77 \pm 1.60^{\mathrm{a}, \mathrm{v}}$ & $29.38 \pm 0.95^{b, y}$ & $31.68 \pm 1.25^{\mathrm{a}, \mathrm{v}}$ & $36.74 \pm 1.34^{b, z}$ & $31.96 \pm 0.93^{\mathrm{a}, \mathrm{v}}$ & $37.68 \pm 1.95 \mathrm{~b}, \mathrm{z}$ \\
\hline ROI 4 & $29.21 \pm 1.59 \mathrm{a}, \mathrm{v}$ & $33.09 \pm 1.36^{b, x}$ & $31.77 \pm 0.88^{\mathrm{a}, \mathrm{v}}$ & $28.62 \pm 1.83^{b, y}$ & $31.73 \pm 1.30^{\mathrm{a}, \mathrm{v}}$ & $36.57 \pm 1.42^{b, z}$ & $31.98 \pm 0.83^{\mathrm{a}, \mathrm{v}}$ & $37.77 \pm 2.26^{b, z}$ \\
\hline ROI 5 & $28.73 \pm 1.47^{\mathrm{a}, \mathrm{v}}$ & $34.33 \pm 1.69^{b, x}$ & $30.77 \pm 1.13^{\mathrm{a}, \mathrm{v}}$ & $35.92 \pm 0.78^{\mathrm{b}, \mathrm{x}}$ & $30.78 \pm 1.39 \mathrm{a}, \mathrm{v}$ & $36.43 \pm 1.07^{b, x}$ & $30.98 \pm 1.26^{\mathrm{a}, \mathrm{v}}$ & $36.66 \pm 1.02^{b, x}$ \\
\hline ROI 6 & $30.69 \pm 3.17^{\mathrm{a}, \mathrm{v}}$ & $34.83 \pm 1.09^{b, x}$ & $31.10 \pm 1.04^{\mathrm{a}, \mathrm{v}}$ & $34.89 \pm 1.68^{b, x}$ & $31.02 \pm 1.54^{\mathrm{a}, \mathrm{v}}$ & $36.64 \pm 1.02^{b, x}$ & $31.15 \pm 1.44^{\mathrm{a}, \mathrm{v}}$ & $35.52 \pm 1.41^{b, x}$ \\
\hline ROI 7 & $30.15 \pm 1.20^{\mathrm{a}, \mathrm{v}}$ & $32.00 \pm 2.01^{b, x}$ & $29.99 \pm 1.00^{\mathrm{a}, \mathrm{v}}$ & $36.44 \pm 3.13^{b, y}$ & $30.45 \pm 1.85^{\mathrm{a}, \mathrm{v}}$ & $37.57 \pm 3.01^{b, y}$ & $30.85 \pm 2.69^{\mathrm{a}, \mathrm{v}}$ & $39.61 \pm 1.25^{b, y}$ \\
\hline ROI 8 & $27.72 \pm 2.27^{\mathrm{a}, \mathrm{v}}$ & $32.55 \pm 2.77^{b, x}$ & $30.46 \pm 0.96^{\mathrm{a}, \mathrm{v}}$ & $33.00 \pm 0.75^{b, x}$ & $30.08 \pm 0.89^{a, v}$ & $33.12 \pm 1.38^{b, x}$ & $30.05 \pm 1.11^{\mathrm{a}, \mathrm{v}}$ & $33.53 \pm 1.39^{b, x}$ \\
\hline ROI 9 & $29.36 \pm 2.78^{a, v}$ & $33.90 \pm 1.90^{b, x}$ & $30.69 \pm 1.09^{\mathrm{a}, \mathrm{v}}$ & $35.16 \pm 1.61^{b, x}$ & $29.77 \pm 1.97^{\mathrm{a}, \mathrm{v}}$ & $34.66 \pm 1.50^{b, x}$ & $30.14 \pm 1.28^{\mathrm{a}, \mathrm{v}}$ & $39.89 \pm 2.30^{b, y}$ \\
\hline ROI 10 & $28.13 \pm 2.13^{\mathrm{a}, \mathrm{v}}$ & $32.35 \pm 3.29^{b, x}$ & $30.44 \pm 1.11^{\mathrm{a}, \mathrm{v}}$ & $34.50 \pm 1.20^{b, x}$ & $30.03 \pm 1.08^{\mathrm{a}, \mathrm{v}}$ & $33.58 \pm 2.53^{b, x}$ & $29.84 \pm 1.53^{\mathrm{a}, \mathrm{v}}$ & $39.93 \pm 1.84^{b, y}$ \\
\hline ROI 11 & $29.12 \pm 2.22^{\mathrm{a}, \mathrm{v}}$ & $34.27 \pm 2.12^{b, x}$ & $26.83 \pm 3.01^{\mathrm{a}, \mathrm{v}}$ & $34.94 \pm 2.26^{b, x}$ & $29.72 \pm 2.51^{\mathrm{a}, \mathrm{v}}$ & $34.06 \pm 2.21^{b, x}$ & $31.36 \pm 1.37^{\mathrm{a}, \mathrm{v}}$ & $39.56 \pm 3.40^{b, y}$ \\
\hline
\end{tabular}


Table 3. The values (mean $\pm \mathrm{SD}$ ) of $\mathrm{T}_{\text {diff }}$ obtained before and after lunging with: freely moving head, rubber band, chambon, and triangle side reins. The values represent the superficial thermographic patterns of regions of interest (ROIs) of the neck (ROIs 1-2), chest (ROIs 5-6), back (ROIs 7-8), and hindquarters (ROIs 9-11). The first superscript letters $\left({ }^{a}, b\right)$ indicate differences between measurements before and after an effort independently for each head and neck position. The second superscript letters $\left({ }^{\mathrm{v}, \mathrm{x}, \mathrm{y}}\right)$ indicate differences between freely moving head and type of lunging aid used before $\left({ }^{\mathrm{V}}\right)$ and after $\left({ }^{\mathrm{x}}, \mathrm{y}\right)$ effort. The differences were significant for $p<0.05$, independently for each row.

\begin{tabular}{|c|c|c|c|c|c|c|c|c|}
\hline \multirow{2}{*}{$\begin{array}{c}\text { Lunging } \\
\text { ROIs }\end{array}$} & \multicolumn{2}{|c|}{ Freely Moving Head } & \multicolumn{2}{|c|}{ Chambon } & \multicolumn{2}{|c|}{ Rubber Band } & \multicolumn{2}{|c|}{ Triangle Side Reins } \\
\hline & Before Lunging & After Lunging & Before Lunging & After Lunging & Before Lunging & After Lunging & Before Lunging & After lunging \\
\hline ROI 1 & $4.74 \pm 0.67^{a, v}$ & $4.17 \pm 1.26^{a, x}$ & $3.40 \pm 0.98^{a, v}$ & $3.69 \pm 0.55^{a, x}$ & $4.36 \pm 0.65^{\mathrm{a}, \mathrm{v}}$ & $4.05 \pm 0.78^{a, x}$ & $5.05 \pm 0.41^{\mathrm{a}, \mathrm{v}}$ & $4.89 \pm 0.73^{a, x}$ \\
\hline ROI 2 & $5.44 \pm 1.29^{\mathrm{a}, \mathrm{v}}$ & $8.22 \pm 0.93^{b, x}$ & $4.78 \pm 0.72^{\mathrm{a}, \mathrm{v}}$ & $3.32 \pm 0.50^{b, y}$ & $5.27 \pm 0.79 \mathrm{a}, \mathrm{v}$ & $2.95 \pm 0.43^{b, y}$ & $5.55 \pm 1.43^{\mathrm{a}, \mathrm{v}}$ & $3.65 \pm 0.78^{b, y}$ \\
\hline ROI 3 & $3.79 \pm 0.57^{a, v}$ & $5.61 \pm 0.74^{b, x}$ & $4.20 \pm 0.53^{a, v}$ & $3.17 \pm 0.48^{b, y}$ & $4.46 \pm 0.45^{\mathrm{a}, \mathrm{v}}$ & $2.90 \pm 0.79 b, y$ & $4.39 \pm 0.46^{\mathrm{a}, \mathrm{v}}$ & $3.24 \pm 0.40^{b, y}$ \\
\hline ROI 4 & $3.83 \pm 0.57^{\mathrm{a}, \mathrm{v}}$ & $4.79 \pm 0.81^{\mathrm{a}, \mathrm{x}}$ & $3.95 \pm 0.78^{\mathrm{a}, \mathrm{v}}$ & $2.76 \pm 0.41^{b, y}$ & $4.27 \pm 0.70^{\mathrm{a}, \mathrm{v}}$ & $2.93 \pm 0.31^{b, y}$ & $4.07 \pm 0.61^{\mathrm{a}, \mathrm{v}}$ & $3.08 \pm 0.46^{b, y}$ \\
\hline ROI 5 & $3.81 \pm 0.56^{\mathrm{a}, \mathrm{v}}$ & $4.46 \pm 0.75^{\mathrm{a}, \mathrm{x}}$ & $3.48 \pm 0.91^{\mathrm{a}, \mathrm{v}}$ & $3.36 \pm 0.61^{a, x}$ & $4.05 \pm 0.33^{\mathrm{a}, \mathrm{v}}$ & $3.91 \pm 0.82^{a, x}$ & $3.30 \pm 0.98^{\mathrm{a}, \mathrm{v}}$ & $4.07 \pm 0.61^{a, x}$ \\
\hline ROI 6 & $3.73 \pm 1.63^{a, v}$ & $4.73 \pm 1.97^{a, x}$ & $3.90 \pm 1.14^{\mathrm{a}, \mathrm{v}}$ & $4.04 \pm 1.80^{\mathrm{a}, \mathrm{x}}$ & $5.48 \pm 0.95^{\mathrm{a}, \mathrm{v}}$ & $3.98 \pm 0.73^{a, x}$ & $4.90 \pm 0.81^{\mathrm{a}, \mathrm{v}}$ & $4.32 \pm 1.15^{\mathrm{a}, \mathrm{x}}$ \\
\hline ROI 7 & $5.17 \pm 1.04^{\mathrm{a}, \mathrm{v}}$ & $7.08 \pm 0.84^{b, x}$ & $5.50 \pm 0.61^{\mathrm{a}, \mathrm{v}}$ & $2.70 \pm 0.49^{b, y}$ & $4.31 \pm 0.46^{\mathrm{a}, \mathrm{v}}$ & $2.07 \pm 1.16^{b, y}$ & $4.84 \pm 1.01^{\mathrm{a}, \mathrm{v}}$ & $3.42 \pm 0.41^{b, y}$ \\
\hline ROI 8 & $4.40 \pm 1.15^{\mathrm{a}, \mathrm{v}}$ & $3.74 \pm 0.94^{\mathrm{a}, \mathrm{x}}$ & $3.77 \pm 1.26^{\mathrm{a}, \mathrm{v}}$ & $3.40 \pm 0.58^{\mathrm{a}, \mathrm{x}}$ & $4.42 \pm 1.12^{\mathrm{a}, \mathrm{v}}$ & $2.93 \pm 0.98^{\mathrm{a}, \mathrm{x}}$ & $4.79 \pm 1.41^{\mathrm{a}, \mathrm{v}}$ & $4.08 \pm 0.46^{\mathrm{a}, \mathrm{x}}$ \\
\hline ROI 9 & $4.79 \pm 0.57^{\mathrm{a}, \mathrm{v}}$ & $4.12 \pm 0.84^{\mathrm{a}, \mathrm{x}}$ & $4.48 \pm 1.33^{\mathrm{a}, \mathrm{v}}$ & $3.88 \pm 1.27^{\mathrm{a}, \mathrm{x}}$ & $4.50 \pm 1.32^{\mathrm{a}, \mathrm{v}}$ & $4.96 \pm 0.54^{\mathrm{a}, \mathrm{x}}$ & $4.78 \pm 0.56^{\mathrm{a}, \mathrm{v}}$ & $2.53 \pm 0.82^{b, y}$ \\
\hline ROI 10 & $4.48 \pm 1.33^{\mathrm{a}, \mathrm{v}}$ & $4.12 \pm 0.84^{\mathrm{a}, \mathrm{x}}$ & $4.76 \pm 0.80^{\mathrm{a}, \mathrm{v}}$ & $3.78 \pm 1.08^{a, x}$ & $5.22 \pm 0.73^{\mathrm{a}, \mathrm{v}}$ & $4.91 \pm 0.82^{\mathrm{a}, \mathrm{x}}$ & $5.04 \pm 0.61^{\mathrm{a}, \mathrm{v}}$ & $2.81 \pm 0.77^{b, y}$ \\
\hline ROI 11 & $4.40 \pm 1.44^{\mathrm{a}, \mathrm{v}}$ & $7.13 \pm 1.23^{b, x}$ & $4.41 \pm 1.78^{\mathrm{a}, \mathrm{v}}$ & $3.90 \pm 1.75^{a, y}$ & $3.87 \pm 1.10^{\mathrm{a}, \mathrm{v}}$ & $3.96 \pm 0.76^{a, y}$ & $4.71 \pm 1.14^{\mathrm{a}, \mathrm{v}}$ & $3.94 \pm 1.30 \mathrm{a}, \mathrm{y}$ \\
\hline
\end{tabular}


In the majority of analyzed ROIs of the neck (ROIs 1-2), chest (ROIs 5-6), back (ROIs 7-8), and hindquarters (ROIs 9-11), the $\mathrm{T}_{\text {mean }}$ increased after lunging with both FMH and LAs $(p<0.001$; Figure $3 \mathrm{~A}-\mathrm{D}$, Figure 4A,B, Figure 5A,B, and Figure 6A-C).

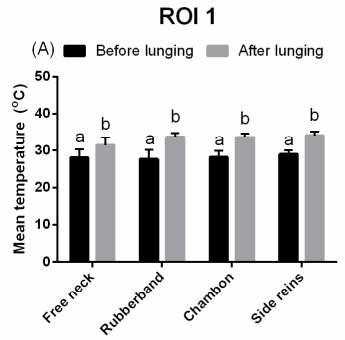

ROI 1

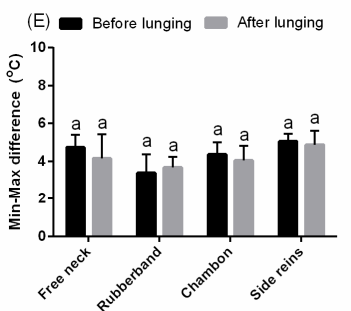

ROI 2

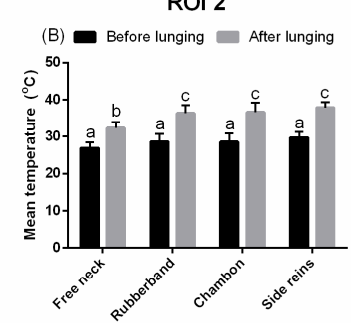

ROI 2

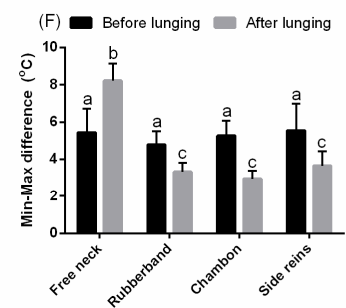

ROI 3

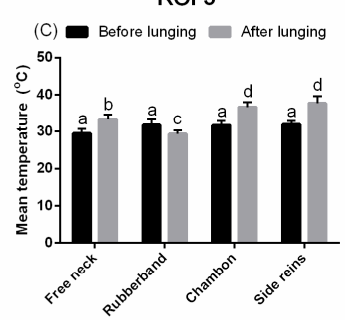

ROI 3

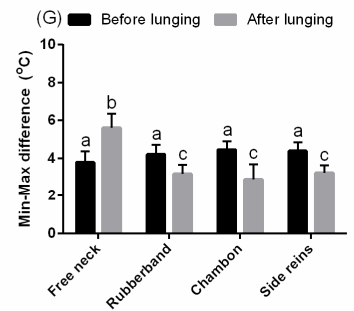

ROI 4

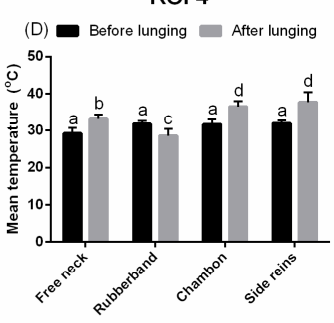

ROI 4

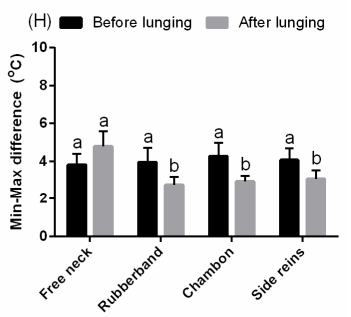

Figure 3. The superficial thermographic patterns of regions of interest (ROIs) of the neck. Horses lunged with: freely moving head, rubber band, chambon, and triangle side reins. (A,E) ROI 1, (B,F) ROI 2, (C,G) ROI 3, (D,H) ROI 4, (A-D) $\mathrm{T}_{\text {mean }},(\mathbf{E}-\mathbf{H}) \mathrm{T}_{\text {diff. Lower case letters indicate differences between }}$ measurements before and after effort, as well as differences among freely moving head and type of lunging aid used. The differences were significant for $p<0.05$. All values were reported as mean + SD.

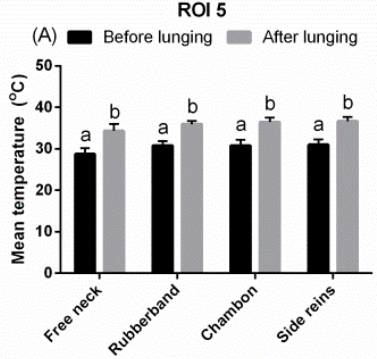

ROI 5

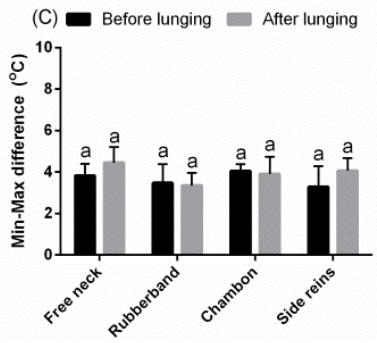

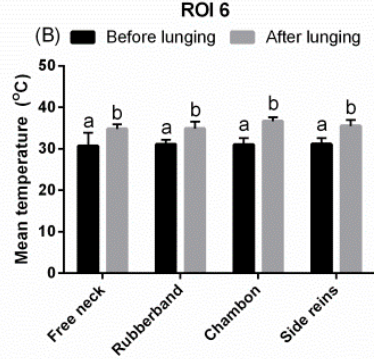

ROI 6

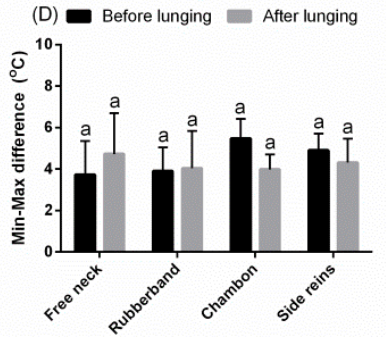

Figure 4. The superficial thermographic patterns of regions of interest (ROIs) of the chest. Horses lunged with: freely moving head, rubber band, chambon, and triangle side reins, before and after effort. (A,C) ROI 5, (B,D) ROI 6, (A,B) $\mathrm{T}_{\text {mean }},(\mathbf{C}, \mathbf{D}) \mathrm{T}_{\text {diff. Lower case letters indicate differences between }}$ measurements before and after an effort, as well as differences among freely moving head and type of lunging aid used. The differences were significant for $p<0.05$. All values were reported as mean + SD.

In the neck regions, $\mathrm{T}_{\text {mean }}$ changed depending on the type of reins in comparison to FMH (Figure 3A-D). After an application of RB, $\mathrm{T}_{\text {mean }}$ was higher in ROI 2 and lower in ROI 3 and ROI $4\left(p<0.05\right.$; Figure 3B-D). After application of CH and TRs, $\mathrm{T}_{\text {mean }}$ was higher in ROIs $2-4(p<0.01$; 
Figure 3B-D). In ROIs 2-4, $\mathrm{T}_{\text {diff }}$ was lower in comparison to FMH, regardless of the type of LAs applied $(p<0.01$; Figure 3E-H). In ROI 1, no differences were observed between fixed and extended HNP for both $\mathrm{T}_{\text {mean }}$ and $\mathrm{T}_{\text {diff }}$ (Figure $3 \mathrm{~A}, \mathrm{E}$ ).
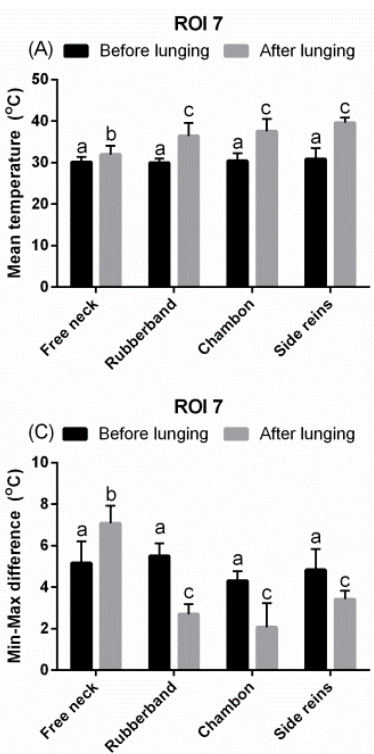
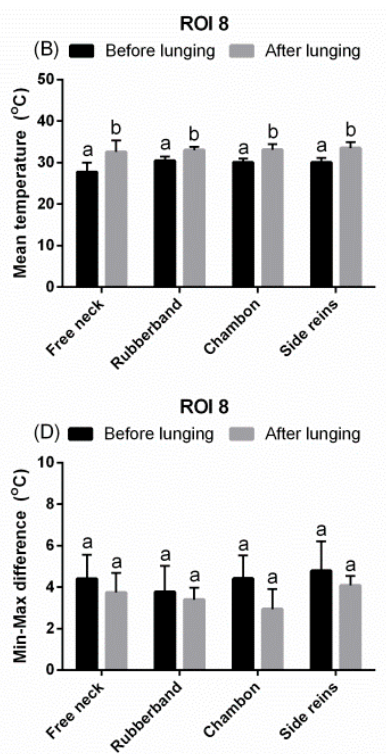

Figure 5. The superficial thermographic patterns of regions of interest (ROIs) of the back. Horses lunged with: freely moving head, rubber band, chambon, and triangle side reins, before and after effort. (A,C) ROI 7, (B,D) ROI 8, (A,B) $\mathrm{T}_{\text {mean }},(\mathbf{C}, \mathbf{D}) \mathrm{T}_{\text {diff. Lower case letters indicate differences between }}$ measurements before and after an effort, as well as differences among freely moving head and type of lunging aid used. The differences were significant for $p<0.05$. All values were reported as mean $+\mathrm{SD}$.

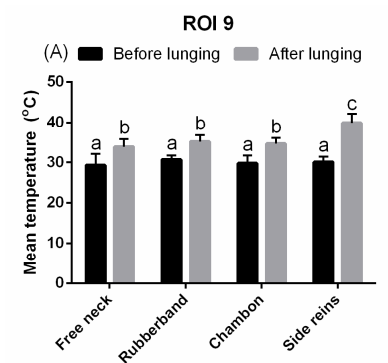

ROI 9

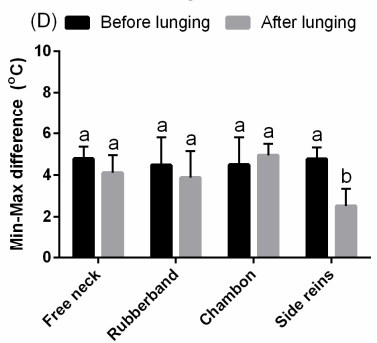

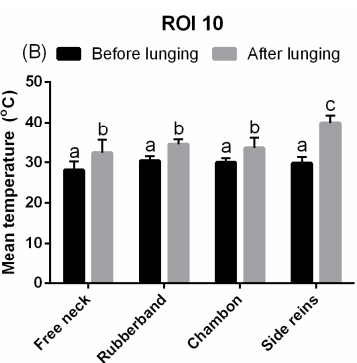

ROI 10

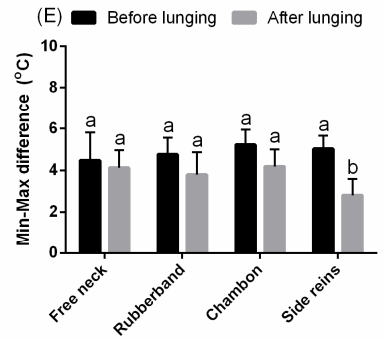

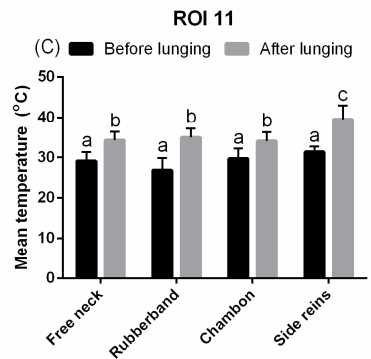

ROI 11

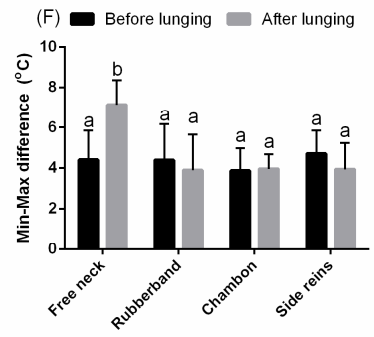

Figure 6. The superficial thermographic patterns of regions of interest (ROIs) of the hindquarters. Horses lunged with: freely moving head, rubber band, chambon, and triangle side reins, before and after effort. (A,D) ROI 9, (B,E) ROI 10, (C,F) ROI 11, (A,B) $\mathrm{T}_{\text {mean },}(\mathbf{C}, \mathbf{D}) \mathrm{T}_{\text {diff. }}$. Lower case letters indicate differences between measurements before and after an effort, as well as differences among freely moving head and type of lunging aid used. The differences were significant for $p<0.05$. All values were reported as mean $+\mathrm{SD}$. 
In ROI 7, $\mathrm{T}_{\text {mean }}$ was higher and $\mathrm{T}_{\text {diff }}$ was lower when horses were lunged with LAs than with FMH, regardless of their type $(p<0.01$; Figure $5 \mathrm{~A}, \mathrm{C})$. However, no differences were observed in the ROI 8 both for $\mathrm{T}_{\text {mean }}$ and $\mathrm{T}_{\text {diff }}$ (Figure $\left.5 \mathrm{~B}, \mathrm{D}\right)$.

The values of $T_{\text {mean }}$ were higher in all three regions of hindquarters (ROIs 9-11) and the $T_{\text {diff }}$ was lower in ROIs 9-10 when horses were lunged with TRs, compared to the other experimental groups $(p<0.0001$; Figure $6 \mathrm{~A}-\mathrm{F})$. Regarding ROI 11, $\mathrm{T}_{\text {diff }}$ only increased when horses were lunged without aids $(p<0.05$; Figure 6F). No other differences were found for any of the parameters and regions analyzed depending on the type of the examined LA (Figure 3E, Figure 4C,D and Figure 5D). Example of pictures depicting thermographic patterns after training session in FMH and with LA is presented in Figure 7.
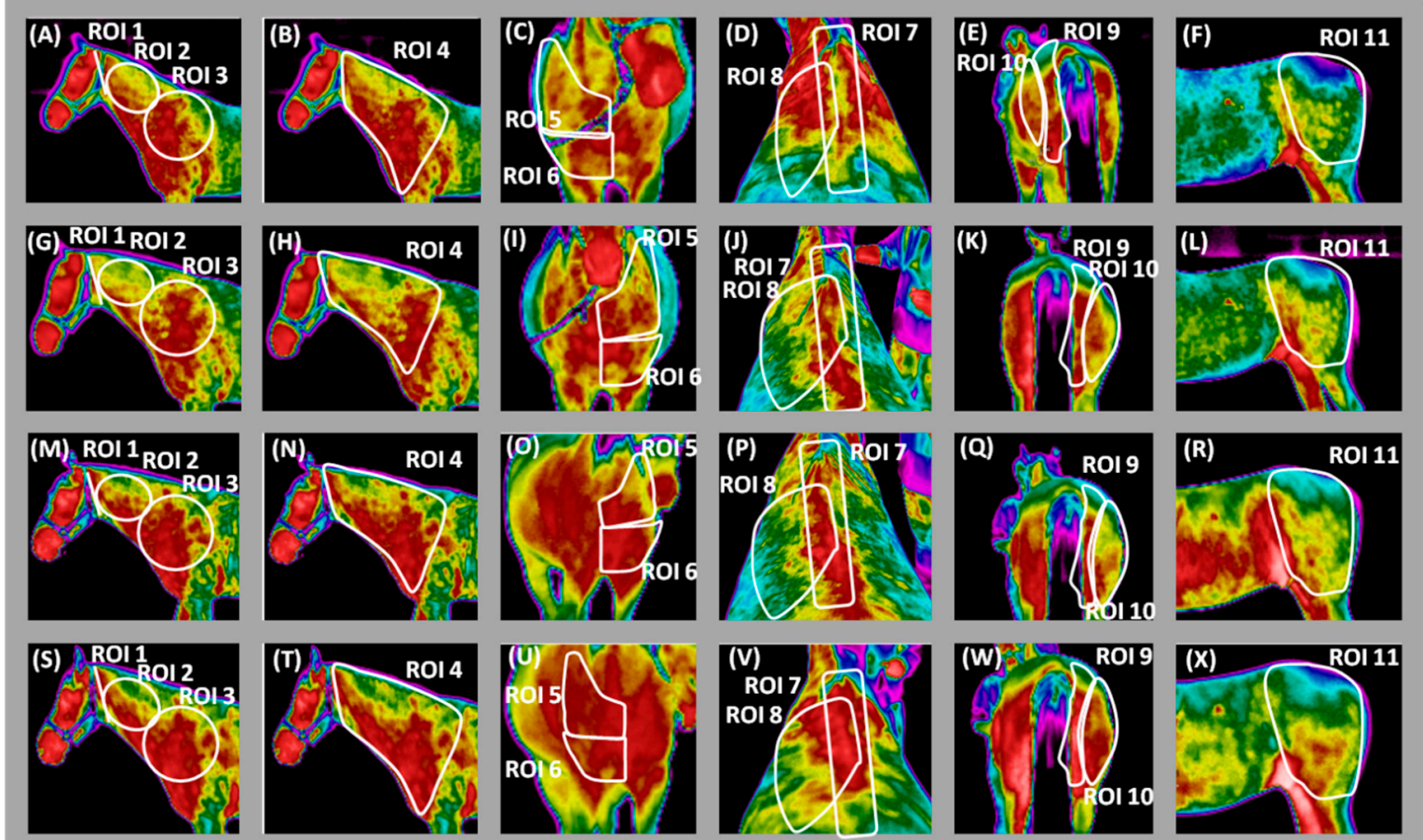

Figure 7. The thermographic images after training session with freely moving head (A-F), rubber band $(\mathbf{G}-\mathbf{L})$, chambon $(\mathbf{M}-\mathbf{R})$, and triangle side reins $(\mathbf{S}-\mathbf{X})$ of the same horse with the marked regions of interest (ROIs) chosen for statistical analysis: (A,G,M,S) ROIs 1-3; (B,H,N,T) ROI 4; (C,I,O,U) ROIs 5-6; (D,J,P,V) ROIs 7-8; (E,K,Q,W) ROIs 9-10; (F,L,R,X) ROI 11.

\section{Discussion}

Leisure horses lunging with all LAs caused an increase in the STP in specific ROIs. These changes seem to be related to the magnitude of physical activity, what stays in line with previous studies on exercised horses $[4,20,21]$. Vertical displacement of anatomic landmarks, such as head, neck, withers, and sacrum, in the sagittal plane, is asymmetric during trotting in a circle, and if it is too intensive or lasts too long, may lead to the overload of the muscles on each side [22] and may lead to the increase of the STP $[15,16]$. The effect of asymmetric forces acting on the horse during lunging may be reduced when the individual horse had developed the mechanisms to deal with it [22]. The mechanisms could slightly differ between horses [22]; however, the possibility of their actions may indicate the welfare of a horses' work on the circle [4,5]. Therefore, the lack of differences between right and left side indicated a correctly selected research methodology, a well-chosen research group (symmetrical patterns before lunging), as well as even work on the lunge (symmetrical patterns after lunging). Moreover, the asymmetric heat distribution is an indicator of malfunctioning horses' mobility in the 
region of the neck [23], chest [15], back [14], and hindquarters [23]. Mean STP increased as the horses were lunged regardless of LA; however, rein type affected the temperature in different ROIs.

The influence of head fixation on the STP in the neck region was previously discussed, with higher $\mathrm{T}_{\text {diff }}$ only in the cranial region of the neck when horses were lunged with a hyperflexed HNP in comparison to FMH [4]. An increase in both $\mathrm{T}_{\text {mean }}$ and $\mathrm{T}_{\text {diff }}$ was noticed when the use of TRs (restriction on head/neck movements), $\mathrm{CH}$ (stiffly limiting the rise of the head), and RB (flexibly limiting the rise of the head) changed the STP of the cranial region of the neck (ROI 2) significantly more than FMH. The head position was stabilized by LAs [24]; therefore, an increase in the blood circulation in the musculature of the cranial region of the neck is understandable. The stabilization of the head position on the bit was considered as a soft restriction of head movement associated with the highest comfort with the open HNA for $\mathrm{CH}\left(\alpha\right.$ : 110-115) or the close HNA for RB and TRs ( $\left(8: 85-90^{\circ}\right)$, which did not cause pain in those angles. We also found no differences in the line from the guttural angle to nape (ROI 1) in $\mathrm{T}_{\text {mean }}$ and $\mathrm{T}_{\text {diff, }}$ but changes depending on the rein type were found in the caudal part of the neck (ROI 3).

When the neck descends in relation to the trunk, head position is controlled by tension in the elastic nuchal ligament (passively) and by tension of musculature (actively) $[25,26]$. Horses may reduce the active muscular input, from $55 \%$ to $31 \%$ of work, by taking advantage of the elastic components energy storage capabilities. In FMH, the nuchal ligament is responsible for all passive work and involved 33\% of work in HNP stabilization [26], whereas LAs may play a role in energy conservation during movement in a manner similar to the nuchal ligament [7]. Our data suggested that the type of LA may affect the capability of elastic energy stored, similarly to the nuchal ligament [26]. When the head/neck descends, LAs are stretched proportionally to their elasticity, then release the energy like a spring when the head/neck raises. We found the lowest $\mathrm{T}_{\text {mean }}$ in ROIs 3-4 when horses were lunged with a compliant elastic RB in opposition to the increase in ROIs 3 and 4 with $\mathrm{CH}$ and TRs (Figures 2 and 3). Based on the increase of $\mathrm{T}_{\text {mean }}$ in those ROIs, it may be concluded that TRs restricted the action of passive anatomical components and promoted the action of epaxial muscles, which may lead to their strengthening [27]. The nuchal ligament is prolonged caudally into the supraspinous ligament, responsible for passive work of the back [26]. Thereby the active muscular input of the back increases, what is visible as an increase of $\mathrm{T}_{\text {mean }}$ in ROI 7 but not in ROI 8, regardless of the LA type. In the previous research, the influence of HNP on the kinematics of the back of ridden horses indicated that restricting movement of the head/neck alters the movement of the back and stride characteristics [3]. High HNP reduces stride length and flexion-extension movement of the caudal back [3]. In our experiment HNP was fixed and lowered, which contributed for an effect on back superficial temperature pattern. The use of the TRs seems to promote not only the action of epaxial muscles, indicated by $\mathrm{T}_{\text {diff }}$ increasing in ROI 7, but may provide a transfer of force between the hindlimbs and the back, indicated by $\mathrm{T}_{\text {mean }}$ increasing in ROIs 9-11 and $\mathrm{T}_{\text {diff }}$ decreasing in ROIs 9-10. Leisure horses often try to compensate insufficient back movement by increasing retraction of the forelimbs [28]. Therefore training exercises should activate the mobility of the back, hence engage hindlimbs motion. The highest engagement of hindlimbs was represented by the highest physical activity of the muscles of the hindquarters, since it was reflected by the highest $\mathrm{T}_{\text {mean }}$ in ROIs 9-11 and the lowest $\mathrm{T}_{\text {diff }}$ in ROIs 9-10 when horses were lunged with TRs.

Lunging with aids has a positive effect on the variability of $\mathrm{T}_{\text {mean }}$ and $\mathrm{T}_{\text {diff }}$ in ROIs $2-3,7,9-10$, whereas lunging in hyperflexion was associated with a less homogenous pattern [4]. When horses were lunged with LAs, it allowed a lower variation of temperature in ROIs 2-4 and ROI 7 in comparison to the pattern before lunging or lunging with FMH. Lunging with TRs was even more beneficial because it additionally changed in thermographic pattern in ROIs 9-10. Lunging without aids was associated with a less variation in STPs in the described regions. Therefore, it may be concluded that horses' work on the lunge with LAs is more beneficial than lunging with a FMH of those horses' daily leisure work. Lunging without aids was associated with less variations in the STPs in described regions; therefore, 
it may be concluded that horses' work on the lunge with LAs is more beneficial than lunging with an FMH. The proper use of LAs activates the axial musculature and raises back mobility [6].

The changes in superficial temperatures may be caused by a combination of physical activity and physiological stress responses $[15,29,30]$, which is not easy to differentiate. Interestingly, infrared thermography has been used to identify physiological stress in horses based on the evaluation of eye temperature [31], which showed positive correlations with heart rate, heart rate variability, stress related behaviors, and cortisol concentration [32]. However, Becker-Birck et al. (2013) concluded that a transient and moderate hyperflexion in horses lunged at moderate speed and not touched with the whip did not elicit a pronounced stress response in horses. They also did not observe overt aversive or stress related behavior of the horse [4]. In the present study, hyperflexion was not used, but instead a much more neutral and stressless HNP with the open HNA $\left(\alpha: 110^{\circ}-115^{\circ}\right)$ and the close HNA (B: $85^{\circ}-90^{\circ}$ ), especially since lunging with LA was not a new element of those horses' daily leisure work. The other conditions of this experiment were comparable; therefore, we can make a cautious assumption that the impact of stress on our results was insignificant. However, in our study the salivary or blood cortisol concentrations, heart rate, heart rate variability, and stress behaviors were not examined. Further investigation regarding the evaluation of eye temperature should be considered.

One of the practical applications of our results relates to the selection of LAs. In our opinion, LAs should be chosen depending on the purpose of training exercises, especially in the leisure type of work. When a leisure horse is working with a beginner rider, the use of LA such as RB is recommended in order to substitute the passive work of equines' neck and back. We support the statement of Clayton et al. (2012) that the elastic component is likely to be a beneficial addition in terms of reducing maximal tension and loading rate [7]. However, when a horse is working on the lunge, TRs seems to be a better option for the improvement of the forward extension of hind limbs and perhaps also the horses' riding quality. After their application, the largest superficial temperature variations were visible for ROIs 3, 4, 7, and, interestingly, ROIs 9-11. Exercises, also understood as lunge work, that target the cervical region may not only have a mobilizing effect on the cervical and thoracolumbar spine, but also activate and strengthen the epaxial and hypaxial muscles throughout the cervical, thoracic, and lumbar regions and thus may alter functional movement patterns [8].

\section{Conclusions}

Thermography was shown as a useful tool in determining changes of STP in horses after lunging, both on LAs and with FMH. Application of different types of LAs changes the STP, and probably also the mobility of horses' neck and back. The choice of LA used in leisure horses lunging should be made individually. Because a small research group was used, we only suppose that the RB may decrease muscle activity of equine neck and back, whereas TRs can play a role in activation of neck, back, and hindquarters mobility. However, regardless of the choice made, LAs improve the thermographic pattern of the leisure horses during work on the lunge, and their proper use is probably more desirable than lunging with FMH.

Author Contributions: Conceptualization, M.M. and M.D.; methodology, M.M.; software, M.M.; validation, M.M. and L.Z.; formal analysis, M.D and T.J.; investigation, M.M., M.D., T.J. and L.Z.; resources, L.Z.; data curation, M.D.; writing—original draft preparation, M.M., L.Z. and M.D.; writing—review and editing, M.M., L.Z. and M.D.; visualization, M.D.; supervision, T.J. and Z.G.; project administration, T.J. and Z.G.; funding acquisition, Z.G. All authors approved final version of manuscript.

Funding: This research received no external funding.

Acknowledgments: This work was conducted in the Veterinary Research Centre WULS (WCB) and the Center for Biomedical Research (CBB) supported by EFRR RPO WM 2007-2013.

Conflicts of Interest: The authors declare no conflicts of interest. 


\section{References}

1. Petsche, V.M.; Derksen, F.J.; Berney, C.E.; Robinson, N.E. Effect of Head position on upper airway function in exercising horses. Equine Vet. J. 1995, 27, 18-22. [CrossRef]

2. Kienapfel, K.; Link, Y.; van Borstel, U.K. Prevalence of different head-neck positions in horses shown at dressage competitions and their relation to conflict behavior and performance marks. PLoS ONE 2014, 9, e103140. [CrossRef] [PubMed]

3. Rhodin, M.; Johnston, C.; Roethlisberger, K.; Wennerstrand, J.; Drevemo, S. The influence of head and neck position on kinematics of the back in ridden horses at the walk and trot. Equine Vet. J. 2005, 37, 7-11. [CrossRef] [PubMed]

4. Becker-Birck, M.; Schmidt, A.; Wulf, M.; Aurich, J.; von der Wense, A.; Mostl, E.; Berz, R.; Aurich, C. Cortisol release, heart rate and heart rate variability, and superficial body temperature, in horses lunged either with hyperflexion of the neck or with an extended head and neck position. JAPAN 2013, 97, 322-330. [CrossRef] [PubMed]

5. Biau, S.; Couve, O.; Lemaire, S.; Barrey, E. The effect of reins on kinetic variables of locomotion. Equine Vet. J. Suppl. 2012, 34, 359-362. [CrossRef] [PubMed]

6. Gómez-Alvarez, C.B.; Rhodin, M.; Bobber, M.F.; Meyer, H.; Weishaupt, M.A.; Johnston, C.; Van Weeren, P.R. The effect of head and neck position on the thoracolumbar kinematics in the unridden horse. Equine Vet. J. 2006, 36, 445-451. [CrossRef]

7. Clayton, H.M.; Kaiser, L.J.; Lavaginino, M.; Stubbs, N.C. Evaluation of intersegmental vertebral motion during performance of dynamic mobilization exercises in cervical lateral bending in horses. Am. J. Vet. Res. 2012, 73, 1153-1159. [CrossRef]

8. Clayton, H.M.; Larson, B.; Kaiser, L.J.; Lavagnino, M. Length and elasticity of side reins affect rein tension at trot. Vet. J. 2011, 188, 291-294. [CrossRef]

9. Daly, J. Recreation and Sport Planning and Design; Human Kinetics: Champaign, IL, USA, 2000; pp. $1825-5076$.

10. Janczarek, I.; Wilk, I. Leisure riding horses: Research topics versus the needs of stakeholders. Anim. Sci. J. 2017, 88, 953-958. [CrossRef]

11. Blokhuis, M.Z.; Lundgren, C. Riders' Perceptions of Equestrian Communication in Sports Dressage. Soc. Anim. 2017, 25, 573-591. [CrossRef]

12. Evans, G.P.; Behiri, J.C.; Vaughan, L.C.; Bonfield, W. The response of equine cortical bone to loading at strains rates experienced in vivo by the galloping horse. Equine Vet. J. 1992, 24, 125-128. [CrossRef] [PubMed]

13. Sleutjens, J.; Smiet, E.; van Weeren, R.; van der Kolk, J.; Back, W.; Wijnberg, I.D. Effect of head and neck position on intrathoracic pressure and arterial blood gas values in Dutch Warmblood ridden horses during moderate exercise. Am. J. Vet. Res. 2012, 73, 522-528. [CrossRef] [PubMed]

14. Arruda, T.Z.; Brass, K.E.; de la Corte, F.D. Thermographic assessment of saddles used on jumping horses. JEVS 2011, 31, 625-629. [CrossRef]

15. Simon, E.L.; Gaughan, E.M.; Epp, T.; Spire, M. Influence of exercise on thermographically determined surface temperatures of thoracic and pelvic limbs in horses. JAVMA 2006, 229, 1940-1944. [CrossRef] [PubMed]

16. Redaelli, V.; Bergero, D.; Zucca, E.; Ferruci, F.; Costa, L.N.; Luzi, F. Use of thermography techniques in equines: Principles and applications. JEVS 2014, 34, 345-350. [CrossRef]

17. Soroko, M.; Jodkowska, E.; Zablocka, M. The use of thermography to evaluate back musculoskeletal responses of young racehorses to training. Thermol. Int. 2012, 22, 152-156.

18. Purohit, R. Standards for thermal imaging in veterinary medicine. Proceedings of XIth European Congress of Thermology. Thermol. Int. 2009, 19, 99. [CrossRef]

19. Moine, S.; Flammer, S.A.; de Jesus Maia-Nussbaumer, P.; Klopfenstein Bregger, M.D.; Gerber, V. Evaluation of the effects of performance dentistry on equine rideability: A randomized, blinded, controlled trial. Vet. $Q$. 2017, 37, 195-199. [CrossRef]

20. Schmidt, A.; Aurich, J.; Mostl, E.; Muller, J.; Aurich, C. Changes in cortisol release and heart rate and heart rate variability during the initial training of three-year-old sport horses. Horm. Behav. 2010, 58, 628-636. [CrossRef]

21. Wijnberg, I.D.; Sleutjens, J.; van der Kolk, J.H.; Back, W. Effect of head and neck position on outcome of quantitative neuromuscular diagnostic techniques in Warmblood ridden horses directly following moderate exercise. Equine Vet. J. 2010, 38, 261-267. [CrossRef] 
22. Pfau, T.; Stubbs, N.C.; Kaiser, L.J.; Brown, L.E.; Clayton, H.M. Effect of trotting speed and circle radius on movement symmetry in horses during lunging on a soft surface. Am. J. Vet. Res. 2012, 73, 1890-1899. [CrossRef] [PubMed]

23. Dunbar, D.C.; Macpherson, J.M.; Simmons, R.W.; Zarcades, A. Stabilization and mobility of the head, neck and trunk in horses during overground locomotion: Comparisons with humans and other primates. J. Exp. Biol. 2008, 211, 3889-3907. [CrossRef] [PubMed]

24. Manfredi, J.; Clayton, H.M.; Rosenstein, D. Radiographic study of bit position within the horses oral cavity. Equine Comp. Exerc. Physiol. 2005, 2, 195-201. [CrossRef]

25. Tokuriki, M.; Aoki, O. Neck muscles activity in horses during locomotion with and without a rider. Equine Exerc. Physiol. 1991, 3, 146-150.

26. Gellman, K.S.; Bertram, J.E.S. The equine nuchal ligament 2: Passive dynamic energy exchange in locomotion. Vet. Comp. Orthop. Traumatol. 2002, 15, 7-14. [CrossRef]

27. Paulekas, R.; Haussler, K.K. Principles and practice of therapeutic exercise for horses. JEVS 2009, 29, 870-893. [CrossRef]

28. De Cocq, P.; Van Weeren, P.R.; Back, W. Effects of girth, saddle and weight on movements of the horse. Equine Vet. J. 2004, 36, 758-763. [CrossRef]

29. Rekant, S.I.; Lyons, M.A.; Pacheco, J.M.; Arzt, J.; Rodriguez, L.L. Veterinary applications of infrared thermography. Am. J. Vet. Res. 2015, 77, 98-107. [CrossRef]

30. Soroko, M.; Śpitalniak-Bajerska, K.; Zaborski, D.; Poźniak, B.; Dudek, K.; Janczarek, I. Exercise-induced changes in skin temperature and blood parameters in horses. Arch. Anim. Breed. 2019, 62, 205-213. [CrossRef]

31. Redaelli, V.; Luzi, F.; Mazzola, S.; Bariffi, G.D.; Zappaterra, M.; Nanni Costa, L.; Padalino, B. The Use of Infrared Thermography (IRT) as Stress Indicator in Horses Trained for Endurance: A Pilot Study. Animals 2019, 9, 84. [CrossRef]

32. Fenner, K.; Yoon, S.; White, P.; Starling, M.; McGreevy, P. The effect of noseband tightening on horses' behavior, eye temperature, and cardiac responses. PLoS ONE 2016, 11, e0154179. [CrossRef]

(C) 2019 by the authors. Licensee MDPI, Basel, Switzerland. This article is an open access article distributed under the terms and conditions of the Creative Commons Attribution (CC BY) license (http://creativecommons.org/licenses/by/4.0/). 